\title{
FACTORS AFFECTING SECONDARY TRAUMATIC STRESS DISORDER AMONG SEARCH AND RESCUE TEAM IN MAKASSAR
}

\author{
Sri Rahayu1, Elly L. Sjattar ${ }^{2}$, Tuti Seniwati ${ }^{3}$ \\ 1,2,3,Faculty of Nursing, Hasanuddin University, Makassar \\ e-mail: rahayu99sri@gmail.com
}

\begin{abstract}
Introduction: Disaster is an unwanted event and usually occur suddenly and is accompanied by many victims. Disasters can have many impacts, both physical and psychological. The psychological impact that can arise on disaster victims is called Post Traumatic Stress Disorder (PTSD). Not only on the victim, the person who served as a helper also can have psychological disorders. Psychological disorders in these helpers are called Secondary Traumatic Stress Disorder (STSD). This study was aimed to identify factors that influence the incidence STSD the Search and Rescue (SAR) teams in universities and BASARNAS Makassar. Method: This research is a quantitative study with a cross-sectional approach using total sampling techniques the samples in this study were all sar and basrnas member $(n=60)$ who agreed to be the respondent and have involved in rescue activity on one last year. Data is collected by distributing questionnaires. Questionnaires used were Secondary Traumatic Stress Scale and Crisis Support Scale. The statistical test used Chi square test, Mann-Whitney U test and logistic regression analysis. Result: The study showed that there was a relationship between the frequency of exposure, social support, and the length of work $(p<0,05)$ and the incidence of STSD. However, the type of exposure has no significant relationship with the incidence of STSD. Conclusion: Social support is the most significant factor compared to the frequency of exposure, the type of disaster and length of work / joining. This research is expected to provide additional information on STSD risk factors. For future researchers, in order to examine other variables which is trauma history and coping mechanism the SAR team to experience symptoms of STSD.
\end{abstract}

Keywords : STSD, SAR Team, Disaster

\section{PENDAHULUAN}

Bencana merupakan suatu peristiwa yang tidak diinginkan dan biasanya terjadi secara mendadak yang disertai dengan jatuhnya banyak korban (Tyas, 2016). Berdasarkan data InaRisk atau Indeks Rawan Bencana Indonesia (IRBI) yang dikeluarkan oleh Badan Nasional Penanggulangan Bencana (BNPB) tahun 2018, indeks risiko rata-rata nasional mencapai 146,3 (BNPB, 2018). Data Informasi Bencana Indonesia (DIBI) yang dikeluarkan oleh BNPB mencatat selama 2017 terdapat 2.866 kejadian bencana di Indonesia. Selama 2018 sampai dengan Agustus 2019 menunjukkan bahwa terdapat 5.384 kejadian bencana dan data bencana untuk Sulawesi Selatan selama 2017 tercatat ada 71 kejadian. Angka ini terus melonjak pada tahun selanjutnya. Dari tahun 2018 hingga Februari 2019 terdapat 268 kejadian.

Bencana yang terjadi dapat memberikan dampak baik fisik maupun psikologis. Dampak yang diakibatkan ini bukan hanya pada korban bencana, tetapi juga termasuk penolong yang membantu proses evakuasi saat atau setelah terjadi bencana. Hal ini dikemukakan oleh Sendler, Rutkowska, \& MakaraStudzinska (2016) bahwa individu 
yang terpapar dengan bencana dapat mengakibatkan terjadinya PTSD. PTSD dapat timbul pada semua umur, jenis kelamin, tingkat pendidikan dan pekerjaan (Nasri, Seniwati, Ilkafah, \& Erfina, 2020).

Seperti halnya PTSD, penolong sebagai individu yang memiliki $\mathrm{n}$ bisa mengalami gejala yang sama. Hal ini disebut Secondary Traumatic Stress Disorder (STSD). STSD ini sangat rentan bagi orang-orang yang menolong dan membantu dalam pengevakuasian penderita trauma. Seseorang yang mengalami STSD dimulai dengan datangnya stressor dan tidak memiliki respon yang baik. Kecemasan semakin meningkat dan jika strategi koping tidak tepat serta menjadi maladaptif, maka akan menimbulkan STSD (Doctor \& Shiromoto, 2010; Townsend, 2012).

Penelitian terhadap tim rescuer di Chiniot dan Faisalabad menunjukkan bahwa tim rescuer mengalami STSD tingkat sedang (Zaidi, Yaqoob, \& Saeed, 2017). Seseorang yang mengalami STSD mengalami gejala seperti intrusion, avoidance dan arousal. Kejadian STSD dilatarbelakangi oleh beberapa faktor risiko yaitu keparahan paparan, frekuensi paparan, riwayat trauma individu dan dukungan sosial (Hensel, Ruiz, Finney, \& Dewa, 2016; Paramitha, Kusristanti, \& Kunci, 2018).

Berhasil atau tidaknya

pencarian dan pertolongan di lapangan sangat dipengaruhi oleh koordinasi antarpotensi SAR itu sendiri (BASARNAS, 2017). Tim SAR yang tergabung dalam BASARNAS maupun Perguruan Tinggi akan selalu memiliki koordinasi dalam proses pencarian dan pertolongan dan berisiko mengalami STSD. Maka dari itu peneliti tertarik untuk mengidentifikasi apa saja faktorfaktor yang mempengaruhi kejadian STSD pada tim SAR Perguruan Tinggi dan BASARNAS Makassar.

\section{METODE}

Penelitian ini merupakan penelitian kuantitatif dengan desain cross sectional. Populasinya adalah seluruh anggota tim SAR Perguruan Tinggi dan BASARNAS Makassar $(\mathrm{N}=60)$. Teknik sampling yang digunakan yakni total sampling, jadi jumlah sampel sebanyak jumlah populasi $(n=60)$. Penelitian dilakukan pada 7-30 November 2019 di sekretariat atau kantor tim SAR, yaitu SAR Unhas, SAR UNM, SAR Universitas Bosowa dan BASARNAS Makassar. Frekuensi paparan, dukungan sosial, jenis operasi lapangan dan lama kerja sebagai variabel independen serta kejadian STSD sebagai variabel dependen penelitian. Data dianalisis menggunakan SPSS versi 16.0 dengan uji statistik yang digunakan pada kejadian STSD dengan variabel frekuensi paparan, dukungan sosial, dan jenis operasi lapangan adalah Chi Square Test, sedangkan untuk variabel lama kerja menggunakan Mann-Whitney U Test.

Instrumen yang digunakan ada 3 yaitu; 1) kuesioner A untuk mengumpulkan data karakteristik responden. 2) Kuesioner B untuk mengukur tingkat dukungan sosial responden dengan menggunakan Crisis Support Scale (CSS) yang dikembangkan oleh Joseph, Andrews, Williams, \& Yule (1992). Kuesioner ini telah diuji valid oleh peneliti menggunakan uji validitas Pearson, dengan cronbach alpha 0,763. 3) Kuesioner C untuk mengukur kejadian STSD responden dengan menggunakan Secondary Traumatic Stress Scale (STSS) yang dikembangkan oleh Bride, Robinson, Yegidis, \& Figley (2004). Kuesioner ini telah diuji valid menggunakan uji validitas Pearson, dengan cronbach alpha 0,777. Izin etik penelitian didapatkan dari Komisi Etik Penelitian Kesehatan Politeknik Kesehatan Makassar dengan No. 1147/KEPK-PTKMKS/XI-2019. 


\begin{tabular}{|c|c|c|c|c|c|}
\hline \multirow{3}{*}{ Karakteristik Responden } & \multicolumn{4}{|c|}{ Kejadian STSD } & \multirow{3}{*}{$\begin{array}{c}\text { Total } \\
\mathbf{f}\end{array}$} \\
\hline & \multicolumn{2}{|c|}{ Mengalami STSD } & \multicolumn{2}{|c|}{ Tidak Mengalami STSD } & \\
\hline & $\mathbf{f}$ & $\%$ & $\mathbf{f}$ & $\%$ & \\
\hline \multicolumn{6}{|l|}{ Jenis Kelamin } \\
\hline Laki-laki & 31 & 66 & 16 & 34 & 47 \\
\hline Perempuan & 6 & 46.2 & 7 & 53.8 & 13 \\
\hline \multicolumn{6}{|l|}{ Organisasi/ Lembaga } \\
\hline BASARNAS Makassar & 20 & 90.9 & 2 & 9.1 & 22 \\
\hline SAR Unhas & 5 & 35.7 & 9 & 64.3 & 14 \\
\hline SAR UNM & 8 & 44.4 & 10 & 55.6 & 18 \\
\hline SAR Uni Bosowa & 4 & 66.7 & 2 & 33.3 & 6 \\
\hline \multicolumn{6}{|l|}{ Riwayat paparan } \\
\hline $\mathrm{Ya}$ & 37 & 94.9 & 2 & 5.1 & 39 \\
\hline Tidak & 0 & 0 & $2 \overline{1}$ & 100.0 & 21 \\
\hline
\end{tabular}

Tabel 1. Distribusi Frekuensi dan Persentase berdasarkan Jenis Kelamin, Organisasi dan Riwayat Trauma

\begin{tabular}{lc}
\hline \multicolumn{1}{c}{ Variabel } & Rerata(SD) \\
\hline Usia & $25.00(5.352)$ \\
Frekuensi Paparan & $3.38(2.906)$ \\
Lama Kerja & $5.47(4.256)$ \\
\hline
\end{tabular}

Tabel 2. Distribusi Responden berdasarkan Usia, Frekuensi Paparan dan Lama Kerja

\begin{tabular}{|c|c|c|c|c|c|}
\hline \multirow[t]{2}{*}{ Pertanyaan } & \multirow[t]{2}{*}{$\begin{array}{l}\text { Gejala } \\
\text { STSD }\end{array}$} & \multicolumn{2}{|c|}{$\begin{array}{c}\text { Tidak } \\
\text { Pernah }\end{array}$} & \multicolumn{2}{|c|}{ Pernah } \\
\hline & & $\mathbf{c}$ & $\%$ & $\mathbf{f}$ & $\%$ \\
\hline $\begin{array}{l}\text { 1. Saya merasa sulit mengekspresikan apa yang saya } \\
\text { rasa }\end{array}$ & Avoidance & 6 & 10.0 & 54 & 90.0 \\
\hline $\begin{array}{l}\text { 2. Jantung saya terasa berdebar-debar ketika } \\
\text { mengingat/memikirkan pekerjaan saya dengan } \\
\text { korban }\end{array}$ & Intrusion & 17 & 18.3 & 43 & 81.7 \\
\hline $\begin{array}{l}\text { 3. Saya merasa seperti merasakan trauma yang dialami } \\
\text { korban }\end{array}$ & Intrusion & 10 & 16.7 & 50 & 83.3 \\
\hline 4. Saya mengalami kesulitan tidur & 11 & 15 & 25.0 & 45 & 75.0 \\
\hline $\begin{array}{l}\text { 5. Saya merasa putus asa/berkecil hati akan masa } \\
\text { depan }\end{array}$ & Avoi & 21 & 35.0 & 39 & 65.0 \\
\hline $\begin{array}{l}\text { 6. Saya merasa terganggu ketika mengingat pekerjaan } \\
\text { saya dengan korban }\end{array}$ & Intrusion & 29 & 48.3 & 31 & 51.6 \\
\hline $\begin{array}{l}\text { 7. Saya merasa tidak begitu tertarik berada di } \\
\text { dekat/sekitar orang lain }\end{array}$ & Avoi & 21 & 35.0 & 39 & 65.0 \\
\hline 8. Saya merasa khawatir/cemas & $\operatorname{Ar}$ & 7 & 11.7 & 53 & 88.3 \\
\hline 9. Saya tidak serajin/seaktif seperti biasanya & Avoi & 10 & 16.7 & 50 & 83.3 \\
\hline $\begin{array}{l}\text { 10. Saya tiba-tiba teringat dengan pekerjaan saya } \\
\text { bersama korban secara spontan }\end{array}$ & Intrusion & 18 & 30.0 & 42 & 70.0 \\
\hline 11. Saya sulit berkonsentrasi & & 14 & 23.3 & 46 & 76.7 \\
\hline $\begin{array}{l}\text { 12. Saya menghindari orang-orang, tem } \\
\text { yang dapat mengingatkan saya deng }\end{array}$ & Avoidance & 24 & 40.0 & 36 & 60.0 \\
\hline $\begin{array}{l}\text { 13. Saya mengalami mimpi buruk tentang pekerjaan } \\
\text { saya dengan korban }\end{array}$ & Intrusion & 26 & 43.3 & 34 & 56.7 \\
\hline $\begin{array}{l}\text { 14. Saya ingin menghindari bekerja dengan beberapa } \\
\text { korban tertentu }\end{array}$ & Avoidance & 31 & 51.7 & 29 & 43.3 \\
\hline 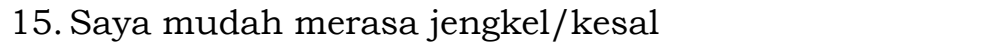 & & 12 & 20.0 & 48 & 80.0 \\
\hline 16. Sa & & 21 & 35.0 & 39 & 65.0 \\
\hline $\begin{array}{l}\text { 17. Saya merasa ada masalah dalam ingatan saya ketika } \\
\text { mengingat interaksi dengan korban }\end{array}$ & Avoidance & 26 & 43.3 & 34 & 56.7 \\
\hline
\end{tabular}

Tabel 3. Distribusi frekuensi dan persentase berdasarkan pernyataan terkait gejala intrusion, avoidance dan arousal 
HASIL

\section{Karakteristik Responden.}

Tabel 1 menjelaskan distribusi responden berdasarkan jenis kelamin, organisasi dan riwayat paparan. Hasil menunjukkan bahwa sebagian besar responden berjenis kelamin laki-laki mengalami STSD yaitu sebanyak 31 orang (66\%). Selain itu, sebagian besar responden yang merupakan anggota BASARNAS Makassar mengalami STSD sebanyak 20 orang $(90,9 \%)$. Dari sini juga menunjukkan bahwa semua responden yang mengalami STSD memiliki riwayat paparan sebelumnya yaitu sebanyak 37 orang $(94,9 \%)$.

Tabel 2 menjelaskan distribusi responden berdasarkan usia, frekuensi paparan dan lama kerja. Hasil penelitian ini menunjukkan bahwa rata-rata responden berusia 25 tahun dan rata-rata frekuensi paparan sebanyak 3 kali paparan dengan rata-rata lama kerja sebagai tim SAR selama 5 tahun.

Tabel 3 menjelaskan tentang frekuensi dan persentase berdasarkan pernyataan terkait gejala intrusion, avoidance dan arousal. Hasil penelitian menunjukkan bahwa pada gejala intrusion, kebanyakan responden sebanyak 50 orang (83\%) merasakan trauma yang dialami korban. Pada gejala avoidance, mayoritas responden sebanyak 54 orang (90\%) merasakan sulit mengekspresikan apa yang dia rasa. Sedangkan pada gejala arousal, kebanyakan responden sebanyak 53 orang $(88,3 \%)$ selalu merasa khawatir atau cemas.

\begin{tabular}{|c|c|c|c|c|c|c|}
\hline \multirow{3}{*}{ Variabel } & \multicolumn{4}{|c|}{ Kejadian STSD } & \multirow[t]{3}{*}{ Total } & \multirow[t]{3}{*}{$\boldsymbol{p}$} \\
\hline & \multicolumn{2}{|c|}{ Mengalami STSD } & \multicolumn{2}{|c|}{ Tidak Mengalami STSD } & & \\
\hline & $\mathbf{f}$ & $\%$ & $\mathbf{f}$ & $\%$ & & \\
\hline \multicolumn{7}{|l|}{ Frekuensi Paparan } \\
\hline Sekali paparan & 2 & 9.5 & 19 & 90.5 & 21 & 0.000 \\
\hline $\begin{array}{l}\text { Lebih dari sekali } \\
\text { paparan }\end{array}$ & 35 & 89.7 & 4 & 10.3 & 39 & \\
\hline \multicolumn{7}{|l|}{ Dukungan Sosial } \\
\hline Tinggi & 7 & 25.0 & 21 & 75.0 & 28 & 0.000 \\
\hline Rendah & 30 & 93.8 & 2 & 6.2 & 32 & \\
\hline \multicolumn{7}{|l|}{ Jenis Operasi Lapangan } \\
\hline Bencana alam & 15 & 60.0 & 10 & 40.0 & 25 & 0.8 \\
\hline Bukan bencana alam & 22 & 62.9 & 13 & 37.1 & 35 & 22 \\
\hline \multicolumn{7}{|l|}{ Gejala STSD } \\
\hline Intrusion & 37 & 64.9 & 20 & 35.1 & 57 & \\
\hline Avoidance & 37 & 61.7 & 23 & 38.3 & 60 & \\
\hline Arousal & 37 & 61.7 & 23 & 38.3 & 60 & \\
\hline
\end{tabular}

Tabel 4. Distribusi Frekuensi dan Persentase berdasarkan Frekuensi Paparan, Dukungan Sosial, Jenis Operasi Lapangan dan Gejala STSD

\begin{tabular}{|c|c|c|c|}
\hline \multirow{3}{*}{ Variabel } & \multicolumn{2}{|c|}{ Kejadian STSD } & $p$ \\
\hline & Mengalami STSD & Tidak Mengalami STSD & \\
\hline & Rerata(SD) & Rerata(SD) & \\
\hline Lama Kerja & $6.76(0.771)$ & $3.39(0.482)$ & 0.041 \\
\hline Frekuensi Paparan & $4.32(3.101)$ & $1.87(1.740)$ & \\
\hline
\end{tabular}

Tabel 5. Distribusi Responden berdasarkan Frekuensi Paparan dan Lama Kerja dengan Kejadian STSD

\begin{tabular}{lcc}
\hline \multicolumn{1}{c}{ Variabel } & Koefisien Regresi & Exp (B) \\
\hline Frekuensi Paparan & -17.945 & 0.741 \\
Dukungan Sosial & -1.165 & 34.748 \\
Lama Kerja & -0.343 & 0.830 \\
\hline
\end{tabular}

Tabel 6. Analisis Faktor-Faktor yang Mempengaruhi Kejadian STSD 


\section{Hubungan frekuensi Paparan, Dukungan Sosial, Jenis Operasi Lapangan dan Lama Kerja dengan Kejadian STSD}

Tabel 4 menunjukkan responden yang memiliki paparan yang lebih dari sekali mengalami STSD paling banyak yaitu sebanyak 35 orang $(89,7 \%)$, dukungan sosial yang rendah 30 orang $(93.8 \%)$, jenis operasi lapangan bukan bencana alam 22 orang $(62,9 \%)$, dan responden yang mengalami gejala intrusion mengalami gejala STSD yaitu 37 orang $(64,9 \%)$. Hasil penelitian juga menunjukkan bahwa terdapat hubungan yang signifikan dan bermakna antara frekuensi paparan dan dukungan sosial dengan kejadian STSD $(p<0,05)$. Selain itu, hasil penelitian menunjukkan bahwa tidak terdapat hubungan yang signifikan antara jenis operasi lapangan dengan kejadian STSD $(p>0,05)$.

Tabel 5 menunjukkan rata-rata responden yang mengalami STSD adalah responden dengan lama kerja selama 7 tahun dan 4 kali paparan. Selain itu, hasil penelitian juga menunjukkan bahwa terdapat perbedaan bermakna antara lama kerja responden yang mengalami STSD dan tidak mengalami STSD $(p<0,05)$.

\section{Analisis Faktor yang Paling Berhubungan}

Tabel 6 menunjukkan bahwa dukungan sosial merupakan faktor yang paling bermakna dengan nilai $\operatorname{Exp}(B)=34.748$ dibandingkan dengan frekuensi paparan dan lama kerja.

\section{PEMBAHASAN}

\section{Gambaran Kejadian berdasarkan Gejala STSD}

Kejadian STSD yang dialami oleh tim SAR memiliki tiga gejala utama, yaitu intrusion, avoidance, dan arousal. Dari penelitian ini menunjukkan bahwa sebagian besar responden mengalami gejala intrusion. Hal ini sejalan dengan penelitian yang dilakukan oleh
Khaerulrizal JY (2016) yang menemukan bahwa kebanyakan responden yaitu sebanyak $72 \%$ pernah mengalami intrusion.

Gejala intrusion yang paling banyak pernah dirasakan oleh responden adalah ikut merasakan trauma yang dialami oleh korban. Hal ini disebabkan karena kegagalan responden dalam bersikap empati dan lebih cenderung memiliki rasa simpati terhadap keadaan yang dialami oleh korban. Adanya rasa simpati yang mendalam berupa rasa iba dan kesedihan terhadap keadaan korban dapat membuat seseorang menjadi cenderung merasakan perasaan yang dialami oleh korban yang biasanya bersifat subjektif dan melibatkan perasaan individu.

Adanya pemicu atau stimulus yang terkait dengan kejadian tersebut juga mempengaruhi orang dengan STSD yang mengingat kembali peristiwa traumatik yang pernah dialami (Othman, A. Z., Dahlan, A., Borhani, S. N., \& Rusdi, 2016). Seseorang dengan STSD biasanya mengalami abnormalitas dalam penyimpanan, pelepasan, dan eliminasi katekolamin yang memengaruhi fungsi otak di daerah amigdala yang justru akan membuat kejadian tersebut disimpan dalam bentuk mimpi buruk (Yosep \& Sutini, 2016). Hal ini yang menyebabkan peristiwa traumatik dapat menjadi stimulus dan menimbulkan reaksi trauma ketika mengingatnya kembali.

Selain gejala intrusion, gejala lain yang juga dialami oleh responden adalah avoidance. Penelitian ini menunjukkan bahwa semua responden pernah mengalami gejala avoidance. Hal ini sejalan dengan penelitian yang dilakukan oleh Duffy, Avalos, \& Dowling (2014) yang menyatakan bahwa sebagian besar responden pernah mengalami gejala avoidance yaitu terdapat $72 \%$.

Gejala avoidance yang paling banyak pernah dirasakan oleh responden adalah kesulitan dalam mengekspresikan apa yang dia rasa. 
Hal ini disebabkan karena adanya penilaian negatif responden terhadap kejadian masa lalu yang dapat menyebabkan rasa takut, tidak berdaya dan malu (Ford, Grasso, Elhai, \& Courtois, 2015). Perasaan takut dan tidak berdaya ini dapat menyebabkan \begin{tabular}{lcr} 
kemampuan & dalam & $\begin{array}{r}\text { menjalin } \\
\text { hubungan }\end{array}$ \\
sekitarnya & dangan & $\begin{array}{r}\text { lingkungan } \\
\text { menyebabkan }\end{array}$ \\
seseorang & \multicolumn{2}{c}{ menjadi sulit }
\end{tabular} mengekspresikan perasaannya.

Gejala STSD yang ketiga adalah arousal. Selain avoidance, penelitian ini juga menunjukkan bahwa seluruh responden juga mengalami gejala arousal. Hal ini sejalan dengan penelitian yang dilakukan oleh Khaerulrizal JY (2016) \& Nasri et al. (2020) yang menemukan bahwa sebagian besar responden pernah mengalami gejala arousal Gejala arousal yang paling banyak pernah dirasakan oleh responden adalah selalu merasa khawatir atau cemas. $\mathrm{Hal}$ ini pula didukung dengan penelitian yang dilakukan oleh Bahris, Sangkala, \& Seniwati (2020) bahwa gejala yang paling sering muncul pada pasca traumatic adalah arousal pada onset 11-13 minggu pasca trauma. Hal ini dapat disebabkan karena adanya rangsangan memunculkan kembali kejadian traumatik secara mendadak dan/atau kembalinya trauma (Regel \& Joseph, 2010).

Faktor biokimia tubuh juga mempengaruhi dimana adanya stimulus dari luar tubuh yang dianggap mengancam atau membahayakan akan dihantar melalui impuls neurotransmitter ke otak. Peningkatan hormon androgen dan norepinefrin serta penurunan serotonin menyebabkan terjadinya pengaruh agresif. Perilaku tersebut dapat membuat ketidakmampuan menjalin hubungan dengan orang lain sehingga membuatnya lebih sensitif dan kesulitan untuk rileks (Yosep \& Sutini, 2016).

\section{Hubungan Frekuensi Paparan dengan Kejadian STSD}

Seseorang yang memiliki paparan kejadian lebih dari sekali akan membuat seseorang untuk berisiko terkena STSD. Hal ini dapat dilihat pada tabel 4 yang menunjukkan bahwa frekuensi paparan memiliki hubungan bermakna terhadap kejadian STSD. Hal ini sejalan dengan penelitian yang dilakukan oleh Hensel, Ruiz, Finney, \& Dewa (2016) menemukan bahwa frekuensi paparan menjadi salah satu faktor yang mempengaruhi terjadinya STSD.

Pada penelitian ini, rata-rata jumlah paparan responden yang mengalami STSD adalah 4 kali paparan. Hal ini disebabkan karena seseorang yang terpapar kejadian traumatis kembali menyebabkan seseorang mengalami ingatan yang berulang. Paparan traumatis berulang yang tidak diinginkan merupakan hal yang membuat seseorang akan mengalami kecemasan dan kekhawatiran berlebihan yang bisa menimbulkan STSD.

\section{Hubungan Dukungan Sosial dengan Kejadian STSD}

Dukungan sosial berpengaruh terhadap kejadian STSD pada tim SAR. Misalnya dengan adanya dukungan moril dari orang-orang sekitar, adanya tempat berbagi suka duka serta memberikan nasihaat berupa solusi terhadap masalah yang dialami. Hal ini dapat dilihat pada Tabel 4 yang menunjukkan bahwa dukungan sosial memiliki hubungan bermakna terhadap kejadian STSD. Penelitian ini sejalan dengan penelitian yang dilakukan Cheng, Wang, Wen, \& Shi, (2014) \& Zang et al. (2017) yang menemukan bahwa rendahnya dukungan sosial menjadi faktor terjadinya STSD.

Dukungan sosial berkaitan cara individu dalam mengontrol dan menekan munculnya tekanan atau stres berkelanjutan yang dialaminya. Hal ini disebabkan karena semakin 
responden memiliki orang-orang yang kuat dan suportif di sekitarnya, maka kemungkinan untuk mengembangkan STSD semakin kecil. Namun ketika responden tidak mempunyai dukungan sosial yang baik, maka responden akan cenderung untuk membuatnya semakin tidak siap atas adanya stimulus atau kejadian yang mengancam.

Dukungan sosial yang rendah membuat individu menjadi tidak siap menghadapi kejadian atau ancaman bagi dirinya. Ketika hal tersebut terjadi, maka keadaan menjadi tidak seimbang yang disebut dengan keadaan krisis. Krisis yang berat menyebabkan kecemasan meningkat dimana dapat berisiko menyebabkan STSD. (Yosep \& Sutini, 2016). Oleh karena itu, semakin tinggi dukungan sosial yang diterima, maka akan semakin rendah gangguan stress yang dialami (Tentama, 2014).

\section{Hubungan Jenis Operasi Lapangan dengan STSD}

Jenis operasi lapangan yang dilakukan oleh tim SAR terbagi atas dua yaitu bencana alam dan bukan bencana alam. Tabel 4 menunjukkan bahwa jenis operasi lapangan tidak memiliki hubungan bermakna terhadap kejadian STSD. Hal ini disebabkan karena pada penelitian ini semua jenis operasi lapangan, baik bencana alam maupun bukan bencana alam akan memiliki risiko untuk menyebabkan seseorang mengalami STSD sehingga tidak terdapat perbedaan diantara kedua kelompok. Hal ini juga ditemukan oleh Quinn et al. (2019) bahwa jenis paparan tidak memiliki hubungan yang signifikan terhadap STSD.

Jenis operasi lapangan ini dapat dilihat dari model stress berdasarkan stimulus. Pendekatan model stimulus ini menganggap stress sebagai ciri dari stimulus yang dianggap mengganggu atau merusak. Namun kelemahan dari stimulus ini adalah kegagalan dalam memperhitungkan cara seseorang berespon terhadap stimulus atau stressor yang ada (Yosep \& Sutini, 2016).

\section{Hubungan Lama Kerja dengan Kejadian STSD}

Lama kerja dengan tim SAR merupakan faktor risiko seseorang mengalami STSD. Seperti yang terlihat pada tabel 5, terdapat perbedaan bermakna antara lama kerja responden yang mengalami STSD dan yang tidak mengalami STSD. Studi ini menunjukkan ratarata lama kerja responden yang mengalami STSD lebih tinggi dibanding dengan yang tidak mengalami STSD. Hal ini karena semakin banyak waktu dihabiskan dengan korban maka semakin besar kemungkinan seseorang memiliki empatik yang tinggi atau merasakan hal yang serupa dengan korban alami (Figley, 2012).

Lama paparan dengan korban menyebabkan stressor semakin kuat. Stress ini juga terjadi karena stressor yang kuat tersebut dan disertai dengan kurangnya dukungan dari berbagai pihak. Sejalan dengan penelitian Kintzle et al., (2013) yang menemukan bahwa seseorang yang tidak mengalami gejala STSD berkaitan dengan durasi paparan, dimana orang yang tidak menghabiskan waktu banyak dengan korban trauma tidak mengalami gejala STSD.

\section{KESIMPULAN}

Penelitian menunjukkan bahwa terdapat hubungan antara frekuensi paparan, dukungan sosial dan lama kerja $(p<0,05)$ dengan kejadian STSD. Akan tetapi, jenis paparan tidak memiliki hubungan bermakna dengan kejadian STSD. Adapun faktor yang paling bermakna adalah dukungan sosial dibanding frekuensi paparan dan lama kerja . Penelitian ini diharapkan dapat menjadi informasi tambahan terkait faktor risiko STSD. Peneliti selanjutnya dapat melihat variabel lain termasuk riwayat trauma, jenis bencana alam dan 
mekanisme koping yang dapat menyebabkan para tim SAR dapat mengalami gejala STSD.

\section{DAFTAR PUSTAKA}

Bahris, S., Sangkala, M. S., \& Seniwati, T. (2020). Overview of Post Traumatic Stress Disorder (PTSD) Symptoms of Post-road Traffic Accident Patients. In Indonesian Contemporary Nursing Journal (Vol. 5).

BASARNAS. (2017). Kerja Sama BASARNAS. Retrieved from basarnas.go.id/kerjasama

BNPB. (2018). Indeks Risiko Bencana Indonesia. InaRISK. Retrieved from http://inarisk.bnpb.go.id/irbi

Bride, B. E., Robinson, M. M., Yegidis, B., \& Figley, C. R. (2004). Development and validation of the Secondary Traumatic Stress Scale. Research on Social Work Practice.

https://doi.org/10.1300/J137v11n03

Cheng, Y., Wang, F., Wen, J., \& Shi, Y. (2014). Risk Factors of Post-Traumatic Stress Disorder ( PTSD ) after Wenchuan Earthquake : A Case Control Study. 9(5), 1-7. https://doi.org/10.1371/journal.pone.0 096644

Duffy, E., Avalos, G., \& Dowling, M. (2014). Secondary traumatic stress among emergency nurses: a cross- sectional study. International Emergency Nursing, 16.

https://doi.org/10.1016/j.ienj.2014.05. 001

Doctor, R. M., \& Shiromoto, F. N. (2010). The Encyclopedia of Trauma and Traumatic Stress Disorders. Retrieved from https: / / books.google.co.id

Figley, C. R. (2012). Traumatology Of Grieving: Conceptual, Theoretical, and Treatment Foundation. Retrieved from https:// books.google.co.id

Ford, J. D., Grasso, D. J., Elhai, J. D., \& Courtois, C. A. (2015). Etiology of PTSD. In Posttraumatic Stress Disorder. https://doi.org/10.1016/b978-0-12801288-8.00003-0

Hensel, J. M., Ruiz, C., Finney, C., \& Dewa, C. S. (2016). Meta-Analysis of Risk Factors for Secondary Traumatic Stress in Therapeutic Work With Trauma Victims Jennifer. Journal of Traumatic Stress, 29(August),

293-300. https://doi.org/10.1002/jts

Joseph, S., Andrews, B., Williams, R., \& Yule, W. (1992). The crisis support scale: Psychometric qualities and further validation. British Journal of Clinical Psychology, 31, 63-73. https://doi.org/10.1016/S01918869(00)00220-8
Khaerulrizal JY, M. (2016). Gambaran Gejala Secondary Traumatic Stress Disorder (STSD) pada Tim Search and Rescue (SAR) BASARNAS Makassar. Skripsi tidak diterbitkan. Makassar; Program Studi Ilmu Keperawatan Universitas Hasanuddin

Kintzle, S., Yarvis, L. T. C. J. S., Usaf, M. S., \& Bride, B. E. (2013). Secondary Traumatic Stress in Military Primary and Mental Health Care Providers. 178(December), 1310-1316.

https://doi.org/ 10.7205/MILMED-D13-00087

Nasri, R. I., Seniwati, T., Ilkafah, \& Erfina, E. (2020). Screening of Post-Traumatic Stress Disorder (PTSD) among Flood Victims in Indonesia. Enfermeria Clinica, 30(2), 345-349. https://doi.org/10.1016/j.enfcli.2019.0 7.115

Othman, A. Z., Dahlan, A., Borhani, S. N., \& Rusdi, H. (2016). Posttraumatic Stress Disorder and Quality of Life among Flood Disaster Victims. Procedia - Social and Behavioral Sciences. https://doi.org/https://doi.org/10.101 6/j.sbspro.2016.10.227

Paramitha, R. G., Kusristanti, C., \& Kunci, K. (2018). Resiliensi Trauma dan Gejala Posttraumatic Stress Disorder ( PTSD ) pada Dewasa Muda yang Pernah Terpapar Kekerasan Trauma Resilience and Posttraumatic Stress Disorder ( PTSD ) Symptoms in Violence-Exposed Young Adults. 6(2), 186-196. Retrieved from https://www.researchgate.net/publicati on/333104410_Resiliensi_Trauma_dan_ Gejala_Posttraumatic_Stress_Disorder_P TSD_pada_Dewasa_Muda_yang_Pernah_ Terpapar_Kekerasan_Trauma_Resilience _and_Posttraumatic_Stress_Disorder_PT SDSymptoms_in_Violence-Exposed_You

Quinn, A., Ji, P., \& Nackerud, L. (2019). Predictors of secondary traumatic stress among social workers: Supervision, income, and caseload size. Journal of Social Work, 19(4), 504-528. https://doi.org/10.1177/14680173187 62450

Regel, S., \& Joseph, S. (2010). Post-traumatic Stress. Retrieved from https://books.google.co.id

Sendler, D. J., Rutkowska, A., \& MakaraStudzinska, M. (2016). How the exposure to trauma has hindered physicians' capacity to heal: Prevalence of PTSD among healthcare workers. European Journal of Psychiatry, 30(4), 321-334.

https://doi.org/10.7490/f1000research. 1111861.1

Tentama, F. (2014). Dukungan Sosial dan PostTraumatic Stress Disorder. 13(2), 133$138 . \quad$ Retrieved from https://ejournal.undip.ac.id/index.php 
/psikologi/article/view/8084/6631

Townsend, M. C. (2012). Preview-OfPsychiatric-Mental-Health-NursingConcepts-of-Care-in-Evidence-BasedPractice. Retrieved from

https://www.amazon.com/Psychiatric-MentalHealth-Nursing-EvidenceBased/dp/0803640927mk/wpcontent/uploads/2017/08/Keperawata n-GAdar-dan-MAnajemen-BencanaKomprehensif.pdf

Yosep, H. I., \& Sutini, T. (2016). Buku Ajar Keperawatan Jiwa. Bandung: Refika Aditama.

Zaidi, S. M. I. H., Yaqoob, N. Y., \& Saeed, H. S. (2017). Compassion Satisfaction Burnout Secondary Traumatic Stress. Journal of Postgraduate Medical
Institute, 31, 314-Tyas, M. D. C. (2016). Keperawatan Kegawatdaruratan dan Manajemen Bencana. Retrieved from http://bppsdmk.kemkes.go.id/pusdiksd 318. Retrieved from https://pdfs.semanticscholar.org/e547/ 91 fa10528c8f9df41e422751e4bea4773d 7e.pdf

Zang, Y., Gallagher, T., McLean, C. P., Tannahill, H. S., Yarvis, J. S., \& Foa, E. B. (2017). The impact of social support, unit cohesion, and trait resilience on PTSD in treatment-seeking military personnel with PTSD: The role of posttraumatic cognitions. Journal of Psychiatric Research, 86, 18-25. https://doi.org/10.1016/j.jpsychires.20 16.11.005 